\title{
Hubungan antara Defek Septum Ventrikel dan Status gizi
}

\author{
Sri Endah Rahayuningsih
}

Bagian Ilmu Kesehatan Anak Fakultas Kedokteran Universitas Padjadjaran, RS Hasan Sadikin, Bandung

\begin{abstract}
Latar belakang. Defek septum ventrikel (DSV) adalah terdapatnya defek pada sekat yang memisahkan ventrikel kiri dan kanan, serta merupakan salah satu penyakit jantung bawaan (PJB). Salah satu komplikasi DSV adalah gangguan status gizi.

Tujuan. Mengetahui apakah terdapat hubungan DSV dengan status gizi serta aspek klinisnya yaitu tipe DSV, ukuran defek, aneurisma septum membranous, prolaps katup aorta, dan. hipertensi pulmonal

Metode. Subjek penelitian ini adalah pasien DSV yang memenuhi kriteria inklusi. Penelitian merupakan penelitian deskriptif analitik dengan rancangan potong lintang yang dilakukan di RS dr Hasan Sadikin Bandung, pada Juli 2007 sampai 30 Juli 2009 dengan analisis statistik menggunakan perhitungan Rasio Odds

Hasil. Terdapat 72,3\% dari 101 anak DSV mengalami malnutrisi. Tidak terdapatnya aneurisma septum membranous $(p=0,005)$, hipertensi pulmonal $(p=0.001)$ berhubungan dengan status gizi. Tipe DSV, ukuran DSV dan prolaps katup aorta tidak berhubungan dengan status gizi.

Kesimpulan. Anak yang menderita DSV sering mengalami gangguan gizi.Terdapat hubungan antara tidak terdapatnya aneurisma septum membranous dan hipertensi pulmonal dengan status gizi.

Sari Pediatri 2011;13(2):137-41.
\end{abstract}

Kata kunci: defek septum ventrikel, status gizi, hipertensi pulmonal

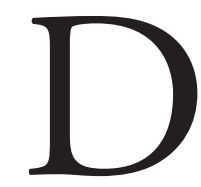
efek septum ventrikel (DSV) merupakan salah satu jenis penyakit jantung bawaan (PJB) yang ditandai oleh adanya defek pada septum ventrikel. Insidensi DSV cukup tinggi, sekitar $20 \%$ dari seluruh PJB. ${ }^{1-4}$

Komplikasi yang sering menyertai DSV adalah hipertensi pulmonal dan gangguan status gizi atau

\section{Alamat korespondensi:}

DR. dr. Sri Endah Rahayuningsih Sp.A(K). Bagian Ilmu Kesehatan Anak Fakultas Kedokteran Universitas Padjadjaran, Jl. Pasteur 38 Bandung 40161. Tel./Fax.: 022-2034426. E-mail: endah.perkani@gmail.com malnutrisi. Malnutrisi pada DSV akan berdampak pada keberhasilan operasi, angka kesakitan serta kematian sebelum dan sesudah dilakukan tindakan operasi koreksi DSV. Tujuan penelitian untuk mengetahui hubungan antara status gizi dengan tipe DSV, ukuran defek, terdapatnya aneurisma septum membranous, prolaps katup aorta dan hipertensi pulmonal.

\section{Metode}

Populasi penelitian adalah pasien DSV datang ke 
Instalasi Rawat Jalan dan Instalasi Gawat Darurat, serta yang dirawat di Instalasi Rawat Inap Bagian Ilmu Kesehatan Anak RS dr. Hasan Sadikin Bandung. Subjek adalah pasien DSV sebagai defek tunggal (isolated), tidak merupakan bagian dari PJB seperti pada tetralogi Fallot, transposisi arteri besar (TAB) atau PJB kompleks yang lain. Diagnosis DSV ditegakkan berdasarkan anamnesis, pemeriksaan fisis, elektrokardiografi, foto toraks, dan ekokardiografi. Kriteria inklusi adalah pasien DSV sebagai defek tunggal (isolated) dan berusia 1 bulan-14 tahun. Kriteria eksklusi adalah pasien DSV dengan kelainan antomi lain atau adanya kelainan bawaan lain, misalnya Sindroma Down

Pemeriksaan ekokardiografi dan Doppler dilakukan oleh seorang konsultan kardiologi anak. Ekokardiografi dilakukan pada anak dalam keadaan tenang atau tidur. Pemeriksaan dilakukan dengan alat ekokardiografi General Electric Type Logic 700 dan General Electric Type Vivid 3. Dilakukan pemeriksaan dengan metode dua dimensi, $M$-mode, dan $M$-mode dengan Dopplerberwarna. Semua hasil pemeriksaan dicetak dan disimpan di dalam CD. Dilakukan pemeriksaan ekokardiografi dua dimensi untuk menegakkan diagnosis DSV, menyingkirkan kelainan kardiak yang lain, dan untuk mengetahui ukuran defek. Diagnosis DSV ditegakkan jika pada pandangan parta sterna sumbu panjang, parasternal sumbu pendek, apikal empat ruang dan subkostal empat ruang terlihat garis yang terputus (dropout) di daerah septum ventrikel. Ukuran DSV ditentukan dengan pemeriksaan ekokardiografi pada sumbu panjang parasternal, defek kecil, bila diameter defek kurang dari 1/3 diameter root aorta pada pandangan sumbu panjang parasternal, defek sedang jika defek lebih dari sepertiga dan kurang dari diameter root aorta, serta defek besar bila diameter defek sama dengan diameter root aorta. ${ }^{5}$ Pengukuran defek dilakukan pada minimal delapan siklus jantung, Semua hasil pengukuran disimpan di dalam CD ekokardiografi 2D digunakan untuk mengetahui adanya aneurisma septum membranous dan prolaps katup aorta. ${ }^{1}$

Hipertensi pulmonal ditegakkan dengan ekokardiografipandangan empat ruang apikal dengan pemeriksaan Doppler berwarna pada DSV dapat dilihat adannya pirau katup trikuspid yang menunjukkan adanya regurgitasi trikuspid. Seperti pada perhitungan pada aliran pirau, kecepatan maksimal aliran pada regurgitasi katup trikuspid juga dapat ditentukan. Perbedaan tekanan sistolik antara atrium dan ventrikel kanan dapat diperhitungkan dengan rumus $\mathrm{P}=4$ V2. Selanjutnya tekanan ventrikel kanan dan arteri pulmonalis juga dapat diperkirakan dengan menambah hasil perhitungan di atas dengan perkiraan tekanan atrium kanan (sekitar 8-10 mmHg).

Status gizi diukur dengan menggunakan kurva Pertumbuhan dari WHO.berat badan/umur. Klasifikasi satus gizi dibagi berdasarkan 4 grup, $z$-scores berat badan/umur -1 sampai 1 dikatakan normal, $z$-scores $<-1$ malnutrisi ringan, $z$-scores $<-2$ as malnutrisi sedang, $z$-scores $<-3$ malnutrisi berat. ${ }^{7}$ Analisis statistic menggunakan perhitungan rasio Odds.

\section{Hasil}

Selama kurun waktu pengumpulan subjek dari Juli 2007 sampai 30 Juli 2009 di Rumah Sakit Dr Hasan Sadikin Bandung, didapatkan 101 anak DSV yang memenuhi kriteria inklusi.

Pada Tabel 1 tampak bahwa jenis kelamin tidak berbeda secara bermakna, sebagian besar kasus DSV adalah tipe perimembran. Pasien DSV dengan ukuran DSV besar, lebih sedikit dibandingkan dengan defek kecil dan sedang. Komplikasi yang sering terjadi pada DSV adalah, hipertensi pulmonal, aneurisma septum membranous, dan prolaps katup aorta.

Gambar 1 memperlihatkan gangguan status gizi, malnutrisi terjadi pada $83 \%$ kasus DSV dan malnutrisi ringan paling sering ditemukan (33\%), sedangkan 27\%

Tabel 1. Karakteristik data

\begin{tabular}{lc}
\hline Karakteritisk data* & $(\%)$ \\
\hline Jenis kelamin & \\
$\quad$ Laki laki & $44(43,6)$ \\
$\quad$ Wanita & $57(56,4)$ \\
Tipe DSV & \\
$\quad$ Perimembran & $80(79,2)$ \\
$\quad$ Muskular & $15(14,8)$ \\
$\quad$ Subaortic doubly commited & $6(6)$ \\
Ukuran DSV & \\
$\quad$ Kecil & $42(41,6)$ \\
$\quad$ Sedang & $42(41,6)$ \\
$\quad$ Besar & $17(16,8)$ \\
Hipertensi pulmonal & $50(49,5)$ \\
Aneurisma septum membranous & $26(25,7)$ \\
Prolaps katup aorta & $9(8,9)$ \\
\hline
\end{tabular}

${ }^{*} \mathrm{~N}=101$ orang anak 
DSV tidak mengalami gangguan status gizi. Gangguan status gizi atau malnutrisi lebih sering terjadi pada DSV dengan komplikasi hipertensi pulmonal (Gambar 2), lebih sering terjadi pada DSV ukuran defek besar (Gambar 3), dan lebih sering terjadi pada DSV tipe perimembran.

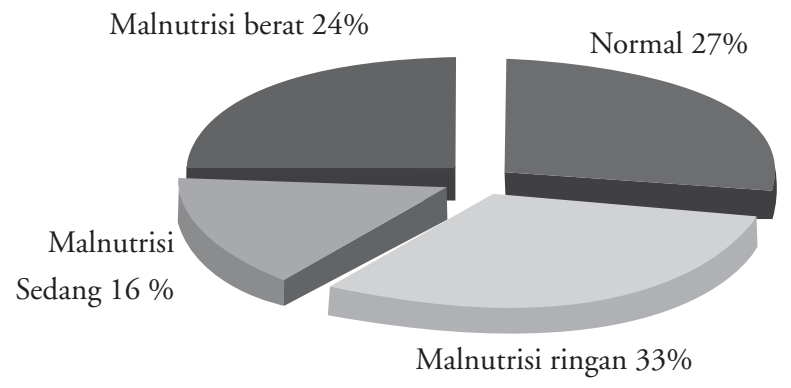

Gambar 1. Distribusi status gizi pada DSV
Malnutrisi lebih sering terjadi pada DSV yang disertai aneurisma septum membranous dan pada DSV tanpa prolaps katup aorta (Gambar 2).

Tipe DSV yang tersering adalah tipe perimembran (Gambar 4)

Analisis logistic multivariate menunjukkan terdapat hubungan antara malnutrisi dengan hipertensi pulmonal dan aneurisma septum membranous. Tidak terdapat hubungan dengan jenis kelamin, tipe DSV, ukuran defek dan prolaps katup aorta.

\section{Pembahasan}

Secara anatomis DSV dapat diklasifikasikan sesuai letak defeknya. Telah banyak klasifikasi yang telah dibuat, salah satunya adalah klasifikasi yang dibuat oleh Forum Ilmiah Kardiologi Anak Indonesia oleh Putra dkk, ${ }^{3}$ yaitu (1) DSV perimembran outlet, inlet, trabekular,

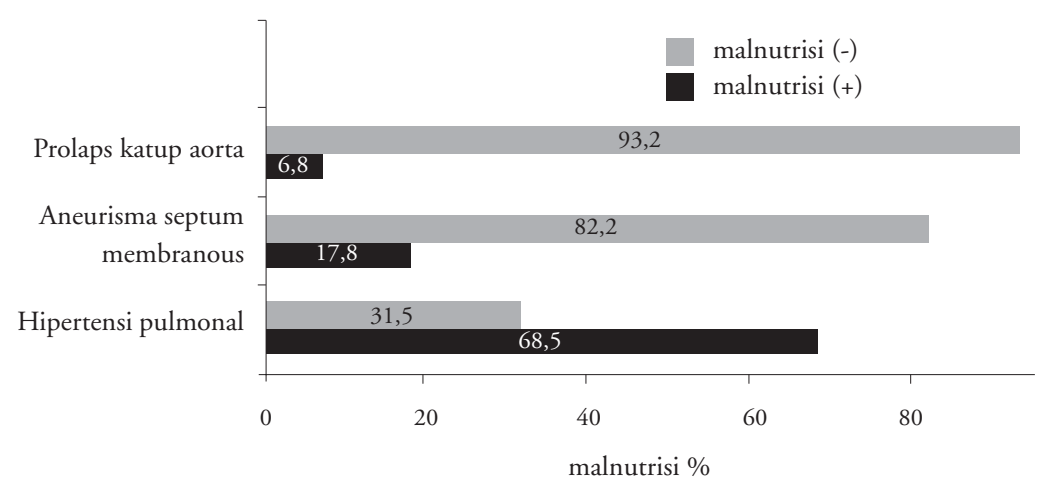

Gambar 2. Proporsi malnutrisi pada DSV dengan komplikasi (prolaps katup aorta, aneurisma septum membranous, dan hipertensi pulmonal)

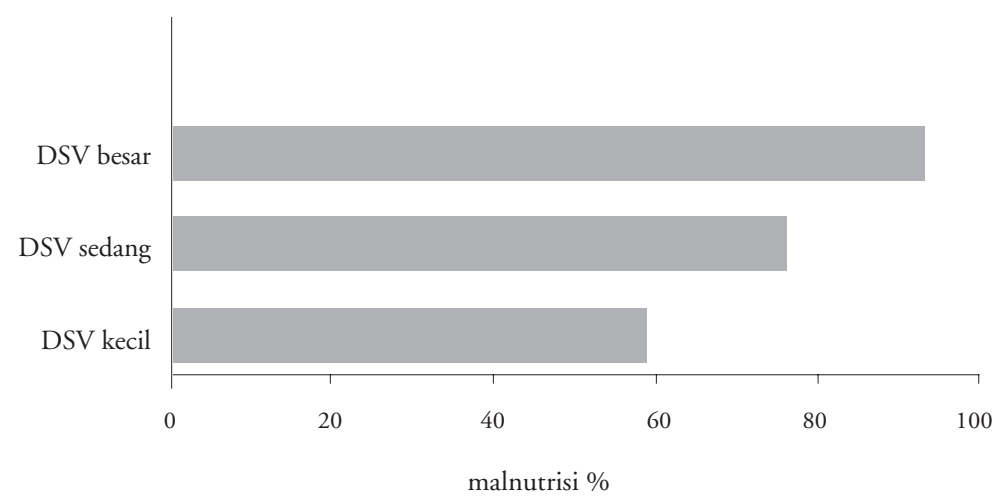

Gambar 3. Proporsi malnutrisi pada ukuran defek DSV 


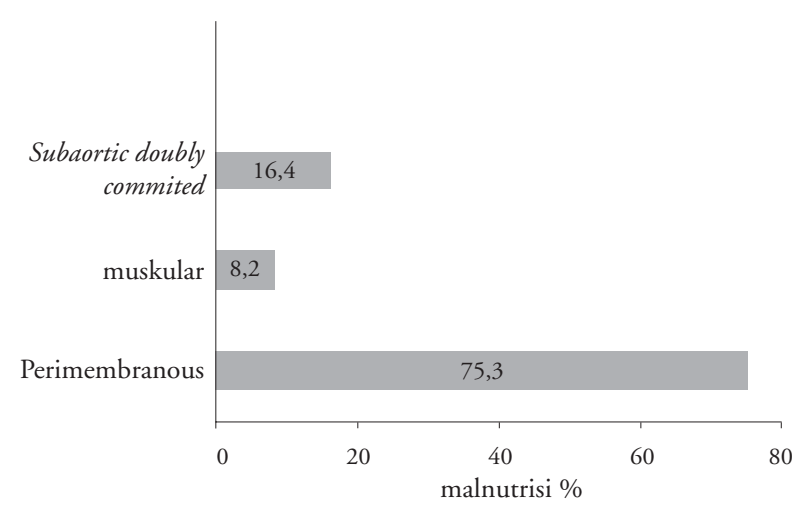

Gambar 4. Proporsi malnutrisi dengan tipe DSV
Ketidakseimbangan energi merupakan faktor utama kegagalan pertumbuhan dan malnutrisi pada anak dengan kelainan jantung bawaan. Secara umum, anak memiliki tingkat metabolisme yang lebih tinggi. Tingkat metabolisme basal bayi hampir dua kali orang dewasa per kilogram berat badan. ${ }^{1}$

Asupan kalori yang tidak adekuat diyakini menjadi penyebab utama terjadinya malnutrisi pada bayi dengan penyakit jantung bawaan. Proses pemberian makan pada bayi dengan kelainan jantung bawaan sama dengan suatu latihan fisik, menuntut peningkatan jumlah energi. Intoleransi terhadap pemberian makan dapat disebabkan ketidakmampuan untuk mengeluarkan cukup energi, ditandai dengan takikardia,

Tabel. 2 Faktor faktor yang berhubungan dengan malnutrsi pada DSV

\begin{tabular}{lcc}
\hline Variabel & Rasio odds (IK 95\%) & $p$ \\
\hline Jenis kelamin & $1,635(0,525-5,088)$ & 0,396 \\
Tipe DSV & $1,053(0,255-4,338)$ & 0,943 \\
Ukuran defek & $1,808(0.668-4,894)$ & 0,243 \\
Hipertensi Pulmonal & $9,678(2,426-38,605)$ & 0,001 \\
Aneurismaseptum membranous & $0,168(0,048-0,582)$ & 0,005 \\
Prolaps katup aorta & $0,570(0,93-3,494)$ & 0,543 \\
\hline
\end{tabular}

*Analisis logistic multivariate

konfluens; (2) DSV muskular posterior, trabekular, infundibular, dan (3) DSV subarterial (doubly commited subarterial) yang disebut juga tipe Oriental oleh karena lebih banyak ditemukan pada orang Asia dibandingkan dengan orang kulit putih. Kami mendapatkan tipe DSV terbanyak adalah perimembran yaitu sebesar 80 anak $(79,2 \%)$ dan tipe yang paling jarang adalah type doubly commited (6\%)

Sejumlah faktor dapat menjadi penyebab terjadinya malnutrisi pada bayi dengan PJB, antara lain hipoksemia, asupan kalori yang tidak adekuat, hipermetabolisme, malabsorbsi, dan faktor hormon pertumbuhan. ${ }^{1}$ Penelitian sebelumnya menunjukkan bahwa status ekonomi, pendidikan orangtua, lamanya mendapat ASI, dan jumlah saudara ternyata tidak berhubungan dangan malnutrisi pada PJB. Hipertensi pulmonal mempunyai hubungan dengan terjadinya malnutrisi pada PJB. Malnutrisi lebih sering terjadi pada PJB sianotik dibandingkan dengan PJB nonsianotik. ${ }^{8}$ Penelitian lain menunjukkan bahwa malnutrisi pada PJB berhubungan dengan intake kalori yang rendah, tipe dari PJB, malabsorbsi, dan hipermetabolisme yang disebabkan oleh gagal jantung kongestif. ${ }^{1,9-13}$ takipnea, sesak napas, dan muntah. Faktor kontribusi lain adalah menurunnya kapasitas lambung yang disebabkan oleh hepatosplenomegali, tertundanya waktu pengosongan lambung, kemampuan menghisap yang tidak terkoordinasi, pola menelan dan bernafas yang abnormal disebabkan oleh takipnea. ${ }^{1}$

Kmi menemukan 83\% kasus DSV yang disertai malnutrisi, agak berbeda dengan penelitian sebelumnya yang menunjukkan hanya 46\% PJB nonsianotik termasuk DSV yang mengalami malnutrisi. ${ }^{8}$ Sebagian besar seri kasus DSV (82\%) yang kami laporkan datang berobat dengan infeksi saluran akut berulang yang akan menyebabkan malnutrisi.

Salah satu komplikasi DSV adalah hipertensi pulmonal, terdapat pada $68,5 \%$ kasus dengan OR $9.678(2,426-38,605)$ dan $\mathrm{p}=0,001$. Temuan tersebut menyokong penelitian sebelumnya yang menyatakan bahwa hipertensi pulmonal merupakan faktor penyebab malnutrisi pada PJB sianotik dan non sianotik. Akibat hipertensi pulmonal, maka akan terjadi pengingkatan aliran darah ke paru dan penurunan aliran darah ke sistemik termasuk ke saluran pencernaan sehingga akan terjadi malabsorbsi. 
Selain hal tersebut, infeksi saluran napas akut berulang juga dapat menyebabkan anoreksia dan menyebabkan gangguan status gizi. Faktor lain yang juga dapat menyebabkan gangguan status gizi pada seorang anak adalah gangguan saluran pencernaan, asupan gizi yang kurang akibat sebab sebab lain, dan faktor faktor lain. ${ }^{1}$

Malabsorpsi merupakan kondisi lain yang memberikan kontribusi bagi malnutrisi yang terlihat pada anak dengan kelainan jantung bawaan. Malabsorpsi merupakan akibat dari hipoksia jaringan gastrointestinal dan menyebabkan intoleransi makan, membatasi asupan kalori, dan penurunan penyerapan nutrisi. Hepatosplenomegali dapat menyebabkan penurunan kapasitas lambung dan asupan nutrisi oral. Anak dengan gagal jantung dapat terjadi edema mukosa dan dinding usus. Perubahan dalam dinding usus akan menyebabkan malabsorpsi. ${ }^{1}$ Pada penelitian ini ditemukan 68,5\% DSV yang disertai dengan hipertensi pulmonal dengan hepatosplenomegali.

Dalam perjalanan alamiah DSV dapat timbul aneurisma septum membranous dan terjadi prolaps katup aorta. Ditemukan malnutrisi lebih sering terjadi pada DSV yang disertai aneurisma septum membranous dan pada DSV tanpa adanya prolaps katup aorta. Kesimpulan anak dengan DSV sering mengalami gangguan satus gizi. Terdapat hubungan antara tidak terdapatnya aneurisma septum membranous dan hipertensi pulmonal dengan DSV.

\section{Daftar pustaka}

1. Kohr LM, Braudis NJ. Growth and nutrition. Dalam: Anderson RH, Baker EJ, Penny D, AN. R, penyunting. Pediatric cardiology. Edisi ke-3. Philadelphia: Churcill Livingstone; 2010.h.1285-98.

2. Park MK. Pediatric cardiology for practitioners, Edisi ke-5. Philadelphia: Mosby; 2008.
3. Putra ST. Pendekatan diagnosis penyakit jantung bawaan sianotik. Dalam: Putra ST, Advani N, Rahayoe AU, penyunting. Dasar-dasar diagnosis \& tatalaksana penyakit jantung pada anak. Forum Ilmiah Kardiologi Anak 1996:131-54.

4. Rahayuningsih SE, Hamanou H, Matsumoto N. Peran mutasi gen CRELD1 pada defek septum ventrikel dan hubungannya dengan manifestasi klinis. Sari Pediatri 2008;10:225-9.

5. Lay W, Mertens L. Echocardiography in pediatric and congenital heart disease, Edisi ke- 1. Philadelphia: WileyBlackwell; 2009.

6. World Health Organization. The WHO child growth standards 2007. Diunduh 14 Januari 2010. Tersedia dari: http;//www.who.int/childgrowth/

7. St Pierre A, Khattra P, Johnson M, Cender L, Manzano $S$, Holsti L. Content validation of the infant malnutrition and feeding checklist for congenital heart disease: a tool to identify risk of malnutrition and feeding difficulties in infants with congenital heart disease. J Pediatr Nurs 2010;25:367-74.

8. Tokel K, Azak E, Ayabakan C, Varan B, Aslamaci SA, Mercan S Somatic growth after corrective surgery for congenital heart disease. Turk J Pediat. 2010;52:58-67.

9. Vaidyanathan B, Radhakrishnan R, Sarala DA, Sundaram KR, Kumar RK. What determines nutritional recovery in malnourished children after correction of congenital heart defects? Pediatrics 2009 ; 124:e294-9.

10. Shrivastava S. Malnutrition in congenital heart disease. Indian Pediatr 2008;45:535-6.

11. CIVIC Study Group from the Spanish Society of Pediatric Cardiology and Congenital Heart Disease. Respiratory infection in congenital cardiac disease. Hospitalizations in young children in Spain during 2004 and 2005: the CIVIC epidemiologic study. Cardiol Young 2007;17:360-71.

12. da Silva VM, de Oliveira Lopes MV, de Araujo TL. Growth and nutritional status of children with congenital heart disease. J Cardiovasc Nurs 2007;22:390-6. 